\title{
World MUSic, VALUe, AND MEMORY ${ }^{1}$
}

\author{
Timothy D. Taylor
}

\begin{abstract}
Value
There is a common narrative among many of us who study musics from other cultures or the history of western music: With the advent or hegemony of capitalism, music became a commodity. And with commodification came the creation of a new form of value, what Marx famously called sexchange-value «. But what about before music becomes a commodity, or isn't a commodity any longer? How can we conceptualize its value? Rather than ignoring the value(s) that musical practices were invested with before they entered the capitalist system, or viewing their values as uncomplicated until they are commodities, or viewing their values as uncomplicated because they are commodities, it is much more useful to think in terms of regimes of value (Appadurai 1986; Myers 2001 and 2002). Cultural goods, whether or not they are commodities, circulate in multiple regimes of value, sometimes simultaneously. The movement between regimes, writes anthropologist Fred Myers, »is a movement between contexts, reorganizing the values of each « (Myers 2002: 360).

The creation of the »world music « »genre« category was, for example, a way of bringing many disparate and unrelated musics into the main regime of value of the western music industry, an economic regime. "Commodification « is what we usually call the complex set of processes by which differ-

1 I would like to thank Steven Feld, who first suggested tackling the literature on value. I would also like to thank Dietrich Helms for inviting me to present this paper at The Languages of Popular Music: Communicating Regional Musics in a Globalized World« at the University of Osnabrück, Germany, September 2014, where I received useful questions and comments from the audience. Thanks also go to Florence Dore, who invited me to present this material at Post45 at the University of North Carolina, Chapel Hill, in October 2014, where I also received useful critiques. Michael Lambek was kind enough to read a version and offer helpful comments, for which I am very grateful. And, as ever, deepest thanks are due to Sherry B. Ortner.
\end{abstract}


ent regimes of value are subordinated to economic regimes or made commensurate with them. But the strategies, forms, and histories of these value transformations vary considerably from one music to the next; commodification is not a single, or simple, phenomenon. Even after a traditional music has been brought into the realm of »world music « - placed in an economic regime of value - that music can exist in other regimes, and not just its former ones. Any music produced as a commodity can still exist in different regimes of value.

We need to conceptualize better the values of music when it is not the result of productive labor in Marx's sense - producing surplus value for capitalists; surely music and other cultural goods that are not the result of productive labor nonetheless possess value (see Lambek 2013). Thus, instead of viewing capitalism as a historical social form that enters the scene and eclipses everything that had gone before, we can begin to understand it as a system of economic value production that competes with existing systems, usually becoming hegemonic, but co-existing and feeding off of other forms of value in complex and never-ending processes.

In anthropology, there have historically been two major ways of comprehending value: as a property of a commodity with use value and exchange value, drawing of course on Marx and post-marxian writings; and the forms of value that accrue from gifts in complex rituals of gift exchange, a line of thinking that goes back to the influential work of Marcel Mauss in the 1920s (Mauss 1990). Briefly recapitulated, Marx posited two forms of the value of commodities: use-value, the utility of a good (whether or not it was a commodity, and whether or not it was produced by human labor); and exchange-value, which is a form of value that enters with the rise of capitalism as goods become commodities produced for the purpose of exchange in a large market. Use-value is heterogeneous, since there are many different uses for many different goods; exchange value is homogenous, measured by the amount of commodities that can be exchanged for another commodity. It is not possible to know or understand use-value through exchange-value, or vice-versa; commodities have a dual character, according to Marx. Additionally for Marx, there was unmarked »value«, defined by socially necessary labor time - the labor theory of value. Mauss's perspective was quite different; for him, the rituals of gift exchange and reciprocity were a way of holding society together, a classic functionalist perspective.

Since these writings, some anthropologists have usefully attempted to bring Marxian and Maussian thinking on value closer together. I have been particularly drawn to those authors who conceive of value as being produced by action, not just action defined as labor or gift exchange. David 
Graeber, for example, writes, „Value is the way our actions take on meaning or importance by becoming incorporated into something larger than ourselves«, and continues,

»First, value is the way actors represent the importance of their own actions to themselves as part of some larger whole. [...] Second, this importance is always seen in comparative terms. Some forms of value are seen as unique and incommensurable; others are ranked [...]; for yet others, such as money in market systems, value can be calculated precisely, so that one can know precisely how many of item A are equivalent to one item B. Third, importance is always realised through some kind of material token, and generally is realised somewhere other than the place it is primarily produced « (Graeber 2005: 451f.).

Michael Lambek (2013) makes a similar point about the importance of action, a result of doing, rather than making something, such as a commodity. Drawing on Aristotle's distinction between making and doing, and Hannah Arendt's discussion of the distinctiveness of action (in Arendt 1998), Lambek argues for a distinction between labor and action, the latter of which can be a source of value. Lambek seeks to distinguish economic forms of value and non-economic ones, which he calls ethical; ethical values are incommensurable with economic values. Lambek (2013: 142) helpfully employs a musical example, the difference between playing the violin for one's own pleasure, and playing it in order to make a living. Both activities have, or produce, value, but not the same sort of value.

These and other anthropological ideas about value can help us understand not only the workings of value in cultures where capitalism is dominant, but in cultures where capitalism is or was emergent. In both cases, however, we need ethnography (and an appreciation of the forces of history) to understand how precisely people conceptualize value and act on their conceptions of it. I am thus, as I have written elsewhere (Taylor n.d.) construing these recent anthropological discussions of value as extending Clifford Geertz's (1973) argument that ethnography should be concerned with what is meaningful for social actors. But many studies of music reproduce over and over the same themes about the role played by music in preor non-capitalist cultures, as well as capitalist ones, reliably (and predictably) concluding that music is an expression of identity, or that music creates and/or reinforces community, or that music produces solidarity, or that music »expresses « culture, and still more. Most such interpretations are functionalist. Many music studies seem to me to be in the place occupied by anthropology once described by Geertz with respect to the study of religion, »in a state of general stagnation« because anthropology continued 
to produce »minor variations on classical theoretical themes «. Geertz concluded his critique by writing that studies that repeat what is already known »may well finally convince a great many people, both inside the profession and out, that anthropologists are, like theologians, firmly dedicated to proving the indubitable« (ibid.: 88 ).

For Geertz, the way beyond this stagnation was to focus on what was meaningful for social actors, which remains a compelling solution. But it needs to be combined not just with Geertzian and (updated Geertzian) conceptions of culture (see Taylor n.d.), apprehended ethnographically or historically. Thinking about value helps us attend to questions of meaning. And considering musical activity as a form of action, a kind of medium of value (Graeber 2001) helps direct attention toward the perspective of the social actors involved.

\section{The Irish Traditional Music Session and Sociality}

Let me turn now to a »world music « practice that I know quite a bit about, and for which I also possess ethnographic data apart from my own long experience - the Irish traditional music session. »Session « refers to an informal gathering of musicians playing Irish traditional dance music, usually in pubs, but occasionally in people's homes (a »house session «). Sessions are informal; they are not concerts, and are seen by musicians as different from gigs, which are paid engagements. The development of the session is fairly recent, an effect of the revival of Irish traditional music in the twentieth century (Hamilton 1999). Since then, Irish music has occasionally been commodified, as represented by some of the major bands such as the Bothy Band, Altan, Dervish, and others, and, perhaps most visibly, in the Riverdance show, and the proliferation of recordings of »Celtic « music. But most Irish traditional music, such as sessions, remains largely outside economic regimes of value, though many hope to be able to make a living from their music, which is elusive even for some professional-level players.

Virtually all the literature about sessions focuses on questions of how sessions build or maintain community (e.g., the session is a »ritual of sharing in which the values of the community are enacted «, Reiss 2003: 148 ), or how they produce or maintain identity, or how they are exercises in the maintenance of status (e.g., "The musical behaviour in a session is largely controlled by the relative status of the people playing, with the higher status musicians exercising more control over the way the session 
develops. Status is conferred by such factors as instrument played, ability, reputation, and age «, Hamilton 1999: 346). ${ }^{2}$

But these are all functionalist interpretations, which is, as I have said, still the norm in many music studies. And they might all be plausible interpretations as far as they go; the means that ethnicizied, racialized, or other marginalized groups can effect a sense of solidarity is not something I would want to minimize. But, following Geertz, we should ask: Why do people do what they do? Why is it meaningful to them? People don't play in sessions to maintain status hierarchies, or express an ethnic or cultural identity. They do it for reasons that are meaningful to them. Asked most simply, what is it that musicians value in Irish traditional music sessions? In a word, sociality.

Over twenty years ago, I conducted a small ethnographic project on the traditional Irish music scene in Ann Arbor, Michigan, of which I was a part. I never published that paper but the voices of the people I interviewed remain with me, for they spoke in powerful and very personal ways about what playing this music meant to them, as it continues to, at least for those with whom I am still in contact. All the musicians I interviewed then, and all of the musicians I have interviewed much more recently, discussed sociality and the communal aspect of playing. Many said something along the lines of having been attracted to the music because of the music (no one I interviewed is ethnically Irish, or if they are, only minimally so and not Irishidentified, and no one grew up hearing or playing the music), but then found that it was the sociality of the scene and the session that kept them coming back.

I should admit here that ethnographic interviewing is always a tricky business. Do the following interviews represent the »real« feelings of my consultants? Whether or not they do, it is important to remember that the aim of ethnography is not necessarily to uncover what is true or not, but what one's interlocutors find to be meaningful. Dissembling reveals what one is invested in, just as telling the truth does, whether one employs a discourse of sociality or something else.

Pam, a fiddler, told me,

»I play Irish music for the social aspect, to meet other musicians and Irish people whether they're players or not. I really enjoy the Irish community. I've found that the people are really nice. And it's an ongoing thing, I've found year in and year out, that you're part of them and they'll invite you and that they'll keep in contact over the years. [...]

2 For a useful examination and critique of the idea of the Irish music session as a community, see O'Shea (2006-7). Thanks are due to Kevin Levine for telling me of this article. 
You go to an Irish establishment quote unquote in the United States, I can feel at home. It's a place where I can know and be known, and understand and be understood on personal levels. When I meet people from Ireland or Scotland who live the music I feel such an instant love for them, and they with me. And it's so instantly reciprocal that it's astounding to me. I don't know, maybe it's a vibe I put out or whatever, I mean, I love this community so much that I just walk in with Valentines you know, and they just pick up on that. $[\ldots]$

I get sentimental and I never used to. It's like, this is my music, these are my people. I feel like I've grown into it, earned it, lived it. I have a home here. It's a very unique feeling. It's something I didn't grow up with. [...]

I can go in to any bar playing the songs I know and the songs I love and feel comforted, real comfort, just real peacefulness. I understand the music, I know the music, and I feel I know the people playing the music even if we've never met. [...]

It's family you know, it's just like a family, with some of the headaches. A lot more comfort and a lot less headaches than a real family. « ${ }^{3}$

Suzanne, a young tin whistle player told me,

»I like very much the community aspect of it. It's so different to just be part of a group that's making music and just playing along. And not to have to be a virtuoso like in the music school. [...] I was really struck, too, by how generous the musicians are, how generous they are in sharing their knowledge."

The musicians with whom I currently play in southern California, over two decades later and across the continent, articulate the same ideas. ${ }^{4}$ Fiddler Melanie Nolley told me,

»I heard something recently about studies that showed that when people get together and do something in a group - I don't know that it was specifically music that they were talking about - but they said that when people get together and engage in a community social activity their heartbeats line up. And I can only imagine that's only what happens when we're in a session. You know that moment when everybody exhales at exactly the same time? When the set [of tunes] is over? That's the power of playing with other people. It's magical, it's really magic. You really do feel better. I feel better when I'm done« (Nolley 2013).

3 This study was conducted before IRB clearance was required of ethnographic studies. I received oral permission from my subjects to conduct these interviews, but will not reveal their full names here.

4 These recent interviews were approved by UCLA's IRB \#11-002035. 
Flute and tin whistle player Peri Holguin echoed the importance of the synergy that occurs at sessions, which has become more of a draw than the music itself.

»What I've learned is that this music - even though I guess I will always want to learn these kind of tunes - is that it's not necessarily about the music but it's now ended up being more about the people that I play with. And the idea that you can just come down and you can just sit down and just play, with no [printed] music - it's an amazing thing, and I think that's really what I think that's what drives a lot of people, it's just more of just coming together and having fun, and getting that synergy going, and playing.«

Elaborating, Peri continued,

»There's nothing to me like when we're all playing and there's that groove that just kicks in, and everybody is smiling or their eyes are rolling back in their heads, and everybody knows where everybody is, and maybe it's in tune, maybe it's not, but the flow, I guess, is there. And that's awesome, there's very few things that could match that experience« (Holguin 2013).

Fiddler Jackie Lang also commented on the social aspect of the scene:

"Somehow the music itself is very social, you go to this and you get ideas from other people's playing, and you get tunes from them, and so it's not just that there are people and there is music, but it's that they are very much intertwined « (Lang 2013).

And tin whistler and concertina player LeeAnn Gorne also spoke about sociality:

»The thing that makes you want to improve, even more than being attracted to the music, is the idea that you're going to be making music with other people. When I was young I was so shy, and I didn't know how to socialize with other people, really. I would just stand around in a bar with a drink in my hand, trying to make conversation with people and it was just excruciating, you know. Now, my chosen social venue makes sense for my personality - you go, and you do what you know how to do. And there's a system to it, there's rules, and kind of an organization to the afternoon, and you can have beautiful music as well, and you get to chat with people, but there's a purpose to it, you know? And that socially makes sense to me« (Gorne 2013).

Irish traditional music at sessions, like many musics made by amateurs for their own pleasure, can thus be characterized as a form of musicalized sociality, but which is part of the larger sociality, what the Irish call the craic (pronounced »crack«) - gossip, telling jokes, entertainment, hanging out, fun - of the session. 
One of my original interlocutors, a young fiddler named Jim, made an important point about how everyone plays the melody in unison (except a guitarist or occasional bouzouki player, who accompanies), which perhaps facilitates the surrender of the self to the group, what Charles Keil has memorably called »the urge to merge $«$ (Keil/Feld 1994: 98).

»With céilí [Irish dance] music, because of the nature of it - everyone playing in unison - there's a certain amount of communication that's going on that's really intense in some ways, you know. And when you're really tuned in with someone else. [...] That's the point, that's why we all do it. That's what makes it so great, is the sensation of losing yourself. [...] Well, not even losing yourself, but of participating in this, a real rush, sort of a drug experience. That's probably why we drink so much when we do it.«

This temporary loss of a sense of self to the group is one of the most powerful ways that sociality is realized, though it doesn't happen at every session.

Here, one could perhaps make a distinction between what brings people together to play, and what they get out of that coming together. But the two are complicatedly intertwined. A typical session involves playing and craic. Music is part of this, not separate from it. What might appear to observers to be a poor session because there seemed to be too much talk and not enough music could well have been experienced by the musicians as a good session because of the nature of the talk (see Kaul 2009 for a discussion of craic at Irish sessions). ${ }^{5}$ Or one could call this, following Durkheim, collective effervescence (Durkheim 1964). The point is, while participating in music might seem to offer something distant from other activities as a session, it is part of the overall activities of the session. It is music that brings people together, but not the only thing that holds them together during a session.

It is perhaps when a stranger visits a session that the communal importance placed on the value of sociality is clearest. A visitor can cause a good deal of instability in a session, particularly those sessions where strangers are rare. Before continuing with this point, however, let me rehearse Georg Simmel's classic discussion of sociability and the distinction between the »wanderer«, »who comes today and goes tomorrow«, and the stranger, »who comes today and stays tomorrow« (Simmel 1971b: 143). The wanderer is no threat to long-term sociality of sessions because they are temporary, but strangers can be considered as threats to sociality since they come from outside of the social world of a particular session and they come to stay.

5 Thanks are due to Kevin Levine for telling me of this book. 
Wanderers and strangers are thus treated differently in sessions. A wanderer, someone who shows up at a session while visiting a different city and who has found a session from thesession.org or another website, is usually treated well, for everyone knows that she will be gone tomorrow. Her musical ability matters, but even a wanderer who is a weak musician would normally be encouraged to play a tune or start a set as a gesture of generosity and welcoming on the part of the host session players. This is done in part for diagnostic purposes, to see how good a player the wanderer is, but also as a way of welcoming the wanderer into the scene. Wanderers who are weak players are tolerated because they are transient, they pose no threat to the social world of the session they visit. And they are usually asked to play a tune or start a set more than once in a session.

Strangers, however, are treated more cautiously. They are new members of the community and therefore need to be integrated (or not) into the social world of a particular session. This takes time. A stranger might be asked to play a tune or start a set when he first arrives, as a wanderer, but such requests normally taper off and the stranger musician is left to decide for himself. Session members' treatments of wanderers and strangers thus help to show just how much sociality matters, even more than musical skill.

But musical skill is important, though, again, how musical skill is managed at sessions helps reveal the value of sociality. It is not simply the case that the best musicians always enjoy the highest status, or that high status is only conferred to the best musicians. At a session I used to frequent on the east coast, a welcomed and fully-fledged member of the session was not one of the top musicians, but he was a celebrated instrument maker and was thus treated with as much respect as the best musicians. Similarly, older musicians in sessions are also treated with great respect regardless of their abilities. Thus, while musical skill clearly matters, musicians frequently award their respect to members of the group who might not play that well.

There is also the issue of musicians who play very well and dominate the session, either through force of personality or through high volume or other musical means. Such musicians can be devalued, despite their skill and even if they possess high status, for such behavior threatens the sociality of the session. In my session, there is a player who attends occasionally who is a virtuoso on several instruments. He usually plays very fast, adds chromaticisms, and frequently jumps up an octave to play over everyone else. Those musicians' who view this sort of behavior negatively express their disapprobation in musical terms; one of my fellow players, an excellent fiddler, once insisted to me quite emphatically that this virtuoso was NOT a good 
musician. In many ways, then, the presence or absence of musical skill is a value that is subordinated to sociality.

This musicians' behavior is an issue of what Simmel, in a different essay, called tact. Sociability, he writes, has no end other than itself, and thus is dependent on its »personal bearers «, and the traits of individuals involved, which determine the »character of purely sociable association « (Simmel 1971a: 130). But, he says, individual personalities must not »emphasize themselves too individually«, for this might threaten sociability (ibid.). What keeps individual personalities in check is what he calls tact, which »guides the self-regulation of the individual in his personal relations to others where no outer or directly egoistic interests provide regulation« (ibid.).

The management of sociality of the Irish session is such that it matters not what one does for a living, how much income one makes, if one has achieved some degree of fame or celebrity, or other such marker of social differentiation. My status as a college professor matters not (though I occasionally act as a kind of clearing house of information for some younger musicians who are thinking about studying music in college or graduate school). Living, and playing, in southern California, we encounter the occasional television or film actor or who comes to play - one such person is a regular; but none of this matters. Simmel calls sociability, and tact, a »very remarkable sociological structure «, for in situations in which sociability is dominant, nothing else matters: »Riches and social position, learning and fame, exceptional capacities and merits of the individual have no role in sociability« (ibid.). Sociality and tact are great social equalizers, at least for the duration of the session. The only differentiating mechanism is musical ability, and even this doesn't much matter if musicians behave tactfully in Simmel's sense.

There might appear to be a fine line between sociality and community in some of these interviews and in my own use of the terms, and so at this point let me explicate the difference as I see it. Community and the functionalist conception of it is a more bounded and self-contained entity than what I am concerned with here; Durkheim was quite clear on this point; in his famous definition of religion, he writes that the »unified system of beliefs and practices « people possess unites them »into one single moral community called a Church « (Durkheim 1964: 47; emphases in original). For Durkheim, »society« was »community written large (Nisbet 1993: 84; emphasis in original). And what holds a community together is its beliefs, its rituals, its division of labor that produces forms of solidarity (Durkheim 1984). I am conceptualizing community more in Simmelian fashion, in which 
»Community « is viewed as a smaller unit with its own dynamics, some of which can be characterized in broad terms, as we have seen. Simmel insisted that the larger workings of culture and society be apprehended through their specific, local manifestations:

"Social life involves the mutual correlation of its elements, which occur in part in instantaneous actions and relations which partly manifest themselves in tangible forms: in public functions and laws, orders and possessions, languages and means of communication. All such social mutual co-relations, however, are caused by distinct interests, ends and impulses. They form, as it were, the matter which realizes itself socially in the snext to each other and ' with each other<, the >for each other< and sagainst each other < of individuals « (quoted by Nisbet 1993: 100).

I am thinking of an Irish traditional music session as a community in this sense, a small scale, »very remarkable sociological structure «, that is governed by the value of sociality and conceptions of tact.

\section{Value and Memory}

Value in the Marxist sense is the product of productive labor stored in commodities, in money. But other forms of value are stored as well, as Graeber notes in the quotation above, even when performance is the medium of value (see also Geertz 1973: 127 on the question of storing meaning in symbols). Commodities are not static objects, and neither are other sorts of value-producing acts such as performances: they can be advertised and anticipated before they happen, they might be reviewed afterward, and remembered and discussed after that.

Acts, according to Lambek (2013: 148), do not produce goods, products, but, he says, consequences. If productive labor results in objects that can be alienated from their producer in the classic Marxian sense, acts such as musical performances can produce narratives that can also circulate, recirculate, and be rewritten. Even after musical groups disband and people die, their work is remembered, curated, passed on. Some concerts are remembered and discussed for years, as obituaries for famous musicians show. I don't think I have ever spoken to a musician who didn't say something like, »Back in the day, this scene was much better than it is today." And as is well known, people's work can be reevaluated after they die, with lesser musicians enjoying greater reputations, or celebrated musicians' reputations waning. In the realm of the visual arts, it is by now something of a cliché that the price of an artist's work will rise after she dies. This is not 
the sort of value I am concerned with here, but the point is that time, and memory, play important roles in every regime of value.

The sort of value I am concerned with here, value-in/as-action, apart from productive labor, while it can be commodified, it is much less likely to be because of the difficulty in doing so. This sort of value is created from human action, and needs to be continually re-created and renewed. Probably the best example for those of us who study music is the vast amount of time and energy spent in US music departments on a very small number of composers and works in the western European classical music tradition, even though only a tiny minority of people on the planet listen to that music. All of those acts of teaching and proselytizing are a measure of those people's valuation of that music.

Performances and rituals store value - in tokens, fetishes, and other material forms, but also in ideas, practices, and deities. Lambek writes that certain core rituals such as the Catholic mass »regenerate the value congealed in the ultimate sacred postulates, gestures, and objects - and they and other rituals circulate value insofar as they invest new persons, relationships, and circumstances with sanctity and place them under new or renewed descriptions « (ibid.: 151). This is no less true than the ritual nature of a classical music concert (see Small 1987), a rock concert, or an Irish traditional music session. All function as mediums of value, regimes different from, while sometimes alongside, regimes of value as determined by socially necessary labor time.

At the session where I play in southern California, value is mainly stored in photographs. There is seldom a week that goes by without a musician or two photographing other musicians and then posting photographs to Facebook; sometimes people post photos to Facebook during the session. I would go so far as to say that taking pictures at sessions has spurred an interest in photography and videography in some musicians, at least at the session with which I am most familiar. From such practices it is clear that sessions are as much about music than being together, being seen together, and showing that one has been together. That is, music is the modality of togetherness, of sociality, the currency of sociality for those involved in Irish traditional music. The rise of social media has allowed Irish traditional musicians to amplify the social aspects of the scene, proclaiming, even advertising, its sociality, realizing value in material form a place apart from where value is created, as Graeber writes in the quotation above. ${ }^{6}$

6 One might wonder why the main tokens of value of an Irish music session are mute photographs. It is almost never the case when audio is recorded and posted somewhere or shared on social media, only photographs, and, occasion- 


\section{Conclusions}

I have been employing some recent perspectives of value as articulated by some anthropologists as a way of attempting to move beyond the simple binary oppositions that are frequently employed to discuss the complex processes of the commodification of music, or the global popularization of particular kinds of music, some of which are lumped under the label »world music «. I have also taken pains in some writings to show just how slow and complex the process of commodification of music is (see, for example, Taylor 2007). Even if we don't much use binaries such as »traditional/ modern « anymore, the ghosts of that and other binaries still hover over newer ones, present but not always articulated, such as »pre-commodified «/commodified, pre-globalization/globalization, and many more that underlie a good deal of recent scholarship about music and other forms of cultural production.

Theories of value can help us to find a more actor-centered way of understanding why people make the music they make, and why they find meaning in the making, and listening. I have found such theories to be, well, valuable. They can help us cut through easy, frequently functionalist, assumptions about music and identity, music and community and more, and help us sharpen our ethnographic and historical sensibilities, help us make more of what our ethnographies and histories tell us. Otherwise, as Geertz warned, our work will only be a series of attempts at proving what is already known.

ally but rarely, video. Audio doesn't reveal who is present, and absent. (Musicians frequently record audio so that they can learn new tunes, but these are private recordings and almost never shared on social media.) In a way, while everyone playing tunes they all know is a form of sociality, another way that sociality is established and reinforced is through the recording of tunes, which is really a kind of gift exchange. Musicians learn new tunes from musicians at other sessions, from teachers, from friends, from recordings, and share them with their fellows. 


\section{Bibliography}

\section{Interviews}

Gorne, LeeAnn (2013). Telephone interview by author. 22 August.

Holguin, Peri (2013). Interview by author. 18 August, Long Beach, CA.

Lang, Jackie (2013). Interview by author. 18 August, Long Beach, CA.

Nolley, Melanie (2013). Skype interview with author. 9 August.

\section{Books and Articles}

Appadurai, Arjun (ed.) (1986). The Social Life of Things. Commodities in Cultural Perspective. New York: Cambridge University Press.

Arendt, Hannah (1998). The Human Condition. Chicago: University of Chicago Press (2nd ed.).

Durkheim, Émile (1964). The Elementary Forms of the Religious Life. Translated by Joseph Ward Swain. London: George Allen and Unwin.

Durkheim, Émile (1984). The Division of Labor in Society. Translated by W. D. Halls. New York: Free Press.

Geertz, Clifford (1973). The Interpretation of Cultures. New York: Basic.

Graeber, David (2001). Toward an Anthropological Theory of Value. The False Coin of Our Own Dreams. New York: Palgrave.

Graeber, David (2005). »Value. Anthropological Theories of Value. "In: A Handbook of Economic Anthropology. Ed. by James G. Carrier. Northampton, MA: Edward Elgar, pp. 439-454.

Hamilton, Colin (Hammy) (1999). "Session.«In: The Companion to Irish Traditional Music. Ed. by Fintan Vallely. Cork: Cork University Press, pp. $345 \mathrm{f}$.

Keil, Charles / Feld, Steven (1994). Music Grooves. Essays and Dialogues. Chicago: University of Chicago Press.

Lambek, Michael (2013). »The Value of (Performative) Acts.«In: HAU: Journal of Ethnographic Theory 3, pp. 141-160.

Mauss, Marcel (1990). The Gift. The Form and Reason for Exchange in Archaic Societies. Translated by W. D. Halls. New York: W. W. Norton.

Myers, Fred R. (ed.) (2001). The Empire of Things. Regimes of Value and Material Culture. Santa Fe, NM: School of American Research Press.

Myers, Fred R. (2002). Painting Culture. The Making of an Aboriginal High Art. Durham, NC: Duke University Press.

Nisbet, Robert A. (1993). The Sociological Tradition. New Brunswick, NJ: Transaction.

O'Shea, Helen (2006-7). "Getting to the Heart of the Music: Idealizing Musical Community and Irish Traditional Music Sessions. «In: Journal of the Society for Musicology in Ireland 2, pp. 1-18.

Paul, Adam (2009). Turning the Tune. Traditional Music, Tourism, and Social Change in an Irish Village. New York: Berghahn Books.

Reiss, Scott (2003). »Tradition and Imaginary: Irish Traditional Music and the Celtic Phenomenon. «In: Celtic Modern: Music at the Global Fringe. Ed. by Martin Stokes and Philip Bohlman. Lanham, MD: Scarecrow Press, pp. 145-169. 
Simmel, Georg (1971a). »Sociability. «In: On Individuality and Social Forms. Ed. by Donald N. Levine. Chicago: University of Chicago Press, pp. 127-140.

Simmel, Georg (1971b). »The Stranger. «In: On Individuality and Social Forms. Ed. by Donald N. Levine. Chicago: University of Chicago Press, pp. 143-149.

Small, Christopher (1987). »Performance as Ritual: Sketch for an Enquiry into the True Nature of a Symphony Concert. «In: Lost in Music: Culture, Style and the Musical Event. Ed. by Avron Levine White. (= Sociological Review Monograph 34). London: Routledge and Kegan Paul, pp. 6-32.

Taylor, Timothy D. (2007). "The Commodification of Music at the Dawn of the Era of >Mechanical Music «. In: Ethnomusicology 51, pp. 281-305.

Taylor, Timothy D. (n.d.). Music, Culture, and Capitalism in a Globalizing World. In preparation.

\begin{abstract}
This article enters the recent theoretical conversation concerning value. Following anthropologist David Graeber's arguments about value, one must learn to see a social world not just as a collection of persons and things - or practices, such as musical ones - but as something that is a project of mutual creation, something collectively made and remade.

This article explores the question of value of cultural forms such as music. How does one understand the value of a particular traditional music before the rise of capitalism, and the same music - constructed as "world music « - in a capitalist marketplace? It is not simply a matter of the commodification of something previously uncommodified, but the shift from one regime of value to another. Taking Irish traditional music as a case study, I argue that, while some Irish traditional music today can be understood as a commodity, most of the music exists in another regime of value in which sociality is what matters to participants. This conception of sociality encompasses the practice of many musicians' sharing of photographs of sessions on social media, and participants' memories of tune sources, teachers, and other sessions.
\end{abstract}

